sequent disintegration of the upper layers of epidermal cells. The deepest, least-cifferentiated cells survived, and scattered excretory cells and sometimes areas of true metaplasia appeared in this region; metaplasia was less frequent and usually less extensive than in explants of 13-day skin. When transferred from high vitamin A to normal medium, both the 13- and 18-day skin eventually reverted to the squamous keratinizing type. Dr. Fell suggested that, in the organ cultures, the skin was subjected to conditions which probably could not be reproduced in the intact animal; thus experiments in vitro with excess vitamin A involved developmental potentialities which perhaps could not have been demonstrated in vivo.

G. H. BoURNE

\section{PHYSICAL STRUCTURE AND ENGINEERING PROPERTIES OF CONCRETE}

$\mathrm{T}$ C. POWERS, who is in charge of fundamental research on the properties of concrete at the laboratories of the American Portland Cement Association, is well known for his work in collaboration with T. L. Brownyard on the distribution of water in set cement. Taking advantage of $\mathrm{Mr}$. Powers's attendance at the Stockholm Conference on Winter Concreting, the Cement and Concrete Association asked him to give a lecture to an invited audience in London on March 1 at the Institution of Civil Engineers. More than seven hundred persons attended, covering a wide range of interests in civil engineering and concrete technology. It is a tribute to Mr. Powers's skill and enthusiasm that the highly specialized subject-matter of his talk was nevertheless received with absorption by his large audience, who were obviously stimulated by the many original observations.

Mr. Powers began by narrowing the field of discussion to the paste of cement and water which binds together the sand and larger aggregate. In his view, the major properties of concrete are largely determined by the paste alone, and the over-riding factor controlling the quality of the paste is the ratio of water to cement in the original mix. As hydration of the cement proceeds, some of the water becomes chemically combined, some is adsorbed in the gel resulting from the hydration, and some remains as free water in the capillaries present in the set mass. The properties of the gel, as quoted by Mr. Powers, are : density, $2 \cdot 15 \mathrm{gm} . / \mathrm{c.c}$; porosity, 26 per cent by volume; and coefficient of permeability to water, $2 \times 10^{-15} \mathrm{~cm}$. $/ \mathrm{sec}$. The last is a remarkable figure for a substance of 26 per cent porosity, being less than is obtained with natural rocks of only 2-3 per cent porosity.

Mr. Powers then went on to elaborate a theory which caused a considerable controversy. It is well known, he said, that Portland cement is composed principally of tricalcium silicate, dicalcium silicate and various aluminates. Cements high in tricalcium silicate hydrate more rapidly and gain strength more quickly than others. This is usually explained by the fact that the aluminates react quickly with water, followed by the tricalcium silicate, while the dicalcium silicate hydrates react only slowly. Nevertheless, the evidence shows that in practical cement there is no preferential hydration of the different minerals. The evidence is threefold: constant specific surface of the gel from 1 day to 14 years; constant heat of reaction per unit of combined water from 1 day to 14 years ; constant ratio of tricalcium to dicalcium silicate, as determined by the X-ray method, from the original cement up to 28 days. Mr. Powers did not offer an alternative theory to account for the differing reactivity of cements of different mineralogical composition.

The strength of the cement paste, on Mr. Powers's theory, is determined by how much of the capillary space is filled with gel. This gel/space ratio can be calculated from the original volumes of cement and water and the degree of hydration of the cement. A good relation was shown, graphically connecting the compressive strength of neat paste and the gel/space ratio. Mr. Powers then went on to use his theory to explain the variable coefficient of thermal expansion of concrete and to consider the bulk permeability and the frost resistance of concrete; especially in dealing with the latter property, it is necessary to allow for the accidental or deliberate entrainment of air during the mixing operation.

The discussion that followed the lecture mostly centred around the question of the differential hydration of cement minerals, and it is clear that this question will exercise the minds of cement technologists for some time to come. In replying to the vote of thanks, Mr. Powers made it clear that his work is not complete and that he had offered it for discussion in the hope that any errors or weaknesses might be repaired.

R. W. NURSE

\section{MOISTURE BALANCE OF THE ATMOSPHERE}

GOR his presidential address to the Royal Meteorological Society, given on April 25, Dr. R. C. Suteliffe chose for his subject "The Moisture Balance of the Atmosphere". With so much expression of opinion, both informed and uninformed, regarding the possible effects of nuclear explosions on weather and the possibility of artificially inducing precipitation from clouds, the subject was clearly a topical one; however, Dr. Sutcliffe, who is deputy-director of the Meteorological Office, had very little to say about the narrow 'rain-making' aspect and concentrated on presenting a broad picture of the various inter-related processes going on in the atmosphere, without an understanding of which attempts to tamper with the weather may lead to confusion and, possibly, disappointment.

After lamenting the tendency for new specialist branches of meteorology and applied meteorology to channel-off research energy from the main stream, which should be concerned with atmospheric processes as a whole and which has been very much neglected, Dr. Sutcliffe made the point that the circulation of water and water vapour in the atmosphere is but one aspect of the 'general circulation' of the air which carries it. The transport of water vapour is governed by the 'macro-dynamics' - that is to say, by the equations of fluid dynamics applicable to largescale movements of air-though processes such as condensation and evaporation affect the application of mechanical principles by reason of alterations produced in the air-density. Precipitation, produced by the coalescence of cloud particles, also reacts back on 
the motion since it affects future evaporation and condensation. If there were no coalescence of cloud particles, there would be clouds everywhere and the behaviour of the atmosphere might be expected to be different in many ways.

Dr. Sutcliffe classified the macro-dynamical processes, that is, processes on the scale of weather systems, as orographic, convective and cyclonic. Cyclonic developments occur mainly in middle latitudes, and he was curious to know why they have the size they are observed to have. It was unfortunate that he could not spare time to discuss theories which purport to explain this fact. In low latitudes a slow circulation of air in the planes of the meridians (the 'Hadley' circulation) evidently plays a large part in the transport of water vapour, as it does in the transport of heat and momentum; however, we also observe relatively small but intense disturbances called tropical cyclones. Dr. Sutcliffe wondered if a typ 3 of general circulation is possible in which the tropical cyclones play a part in low latitudes similar to that played by the extra-tropical cyclones (depressions) in middle latitudes. $\mathrm{He}_{\Theta}$ claimed that, with the use of some imagination, one could see indications on climatic mean charts supporting this view.

A fact of some significance concerning the relation between rainfall and other processes going on in the atmosphere is the relatively small 'capital' of water vapour in the atmosphere as compared with the 'turnover'. Dr. Sutcliffe pointed out that there is, on the average, in the whole atmosphere, a total water content equivalent to only about ten days supply of rain. It follows that the total rate of rainfall must be rather closely controlled by the total rate of evaporation. Evaporation requires not only a supply of water but also a large supply of energy, and for control of weather over longer periods we have to look to those large reservoirs of both water and thermal energy, the oceans. The amount of energy required for evaporation is actually comparable with the infra-red radiation from the Earth's surface, and this led Dr. Sutcliffe to a discussion of the rather complicated energy-budget of the atmosphere. In drawing up a balance-sheet we have to use information derived in a variety of ways, some direct and some indirect, and little of it completely reliable. We are concerned. not only with evaporation and precipitation and the convective transport of heat by air motions but also with radiative transfer in both the visible and infrared regions. Various workers have attempted to draw up such a budget; but in many cases some entry has been made which is based more or less arbitrarily and uncritically on the work of others, and sometimes it is difficult to discover by whom and on what evidence a particular estimate was originally made. Dr. Suteliffe paid special attention to some very recent calculations by Budyko of the energy balance of the atmosphere as a whole. Finally, he produced an estimate of evaporation and precipitation over land and over sea as a function of latitude. There appears to be only a very rough agreement between the estimates produced by different people at different times.

Appropriately, in view of the close inter-relation between different processes going on in the atmosphere, Dr. Sutcliffe ended by considering the relation between the local energy balance and weather systems. Energy supply to the atmosphere is deficient in anticyclones because less latent heat of condensation is released. It seems reasonable to suppose that they act as energy 'sinks', towards which energy is trans- ported by air motion, and a more detailed analysis might indicate that their existence actually controls the development of new motions. It is not evident that the large anticyclones need always remain, even on average, in the same places, and Dr. Sutcliffe considered it possible that the atmosphere has more than one pattern of 'general circulation'. The idea is intriguing, and it is to be hoped that it will be followed up in the series of discussions on 'general circulation' problems, which, Dr. Sutcliffe announced, is being planned by the Royal Meteorological Society. One such discussion has already been held after the presentation to the Society of a brilliant theoretical paper by Dr. N. Phillips, of Princeton (see Nature, July 21, p. 129). Dr. Phillips has shown that very many observed features of the behaviour of the atmosphere are reproduced in the numerical integration of the equations governing a very simple model of the atmosphere. The prospects of transforming meteorology into an exact science are very much brighter now than they have ever been in the past.

E. T. EADY

\section{UNIVERSITIES OF GREAT BRITAIN}

\section{CONFERENCE}

$\triangle T$ the 1955 Conference of the Universities of A Great Britain and Northern Ireland, held during December 16-17, a number of topics were discussed, one of which, the age-group 'bulge' and its possible effect on university policy, has been reported in these columns (Nature, January 21, p. 115). The full report of the Conference proceedings, which has now been published*, summarizes the speeches and discussion at this session, and also those of the two preceding sessions on, respectively, the transition from the sixth form at school to the university and the financing of research in universities by outside bodies.

The first session was opened by speeches from Mr. H. D. P. Lee, headmaster of Winchester College, Miss K. Anderson, headmistress of the North London Collegiate School, and Prof. N. F. Mott, of Cambridge. Mr. Lee, starting from the findings of the report on university entrance requirements, claimed that we must not specialize at the expense of general education and that the latter includes, first, a certain minimum of academic achievement such as a certain standard in elementary mathematical operations, a certain ability to understand and write good English and some knowledge of a foreign language, as well as, secondly, at the level of the sixth form, an awareness of the place of specialized study in the field of human knowledge as a whole. He maintained that general education could not be provided at the university itself; it must be given in the schools. Miss Anderson outlined the problems of girls' schools more particularly, and referred to the growing tendency for consultation between the schools and the universities. She suggested that the schools could do more to develop individual responsibility for work. Prof. Mott stressed the importance of framing university entrance requirements and entrance scholarships to encourage the schools to provide time in the sixth forms, along with specialization, to

- Report of the Proceedings of the 1955 Conference of the Universities of Great Britain and Northern Ireland. Pp. 112. (London Association of the Universities of the British Commonwealth, 1956.) 3s. $6 d$. 